Review

\title{
Exosomes for Immunoregulation and Therapeutic Intervention in Cancer
}

\author{
Xuan Zhang ${ }^{1}$, Zenglin Pei ${ }^{1}$, Jinyun Chen ${ }^{2}$, Chunxia Ji1 ${ }^{1}$ Jianqing $\mathrm{Xu}^{1}$, Xiaoyan Zhang ${ }^{1}$, Jin Wang1, \\ 1. Scientific Research Center, Shanghai Public Health Clinical Center, 2901 Caolang Road, Jinshan District, Shanghai 201508, China; \\ 2. Departments of Epidemiology, The University of Texas M.D. Anderson Cancer Center, Houston, TX 770030, USA. \\ $\triangle$ Corresponding author: Jin Wang, Ph.D. Scientific Research Center, Shanghai Public Health Clinical Center, 2901 Caolang Road, Jinshan District, Shanghai \\ 201508, China; Ph: 86-21-37990333-7336; Fax: 86-21-57247094; Email: wangjin@shaphc.org
}

() Ivyspring International Publisher. Reproduction is permitted for personal, noncommercial use, provided that the article is in whole, unmodified, and properly cited. See http://ivyspring.com/terms for terms and conditions.

Received: 2016.01.01; Accepted: 2016.04.26; Published: 2016.05.25

\begin{abstract}
Exosomes, as a subset of extracellular vesicles, function as a mode of intercellular communication and molecular transfer, and facilitate the direct extracellular transfer of proteins, lipids, and miRNAs/mRNAs/DNAs between cells. Cancers have adapted exosomes and related microvesicles as a pathway that can suppress the immune system and establish a fertile local and distant environment to support neoplastic growth, invasion, and metastasis; these tumor-derived exosomes affect immunoregulation mechanisms, including immune activation and immune suppression. Immune cell-derived exosomes can modulate the immune response in cancer, which supports the belief that these membranous vesicles are immunotherapeutic reagents. In this review, we discuss the recent advances in the cancer immunotherapy, roles of exosomes in cancer, immunoregulation of tumor-derived exosomes, and immunomodulation by immune cell-derived exosomes. The topics covered here highlight novel insights into the development of efficient exosome-based cancer vaccines for cancer therapeutic intervention.
\end{abstract}

Key words: Exosomes; cancer; immunoregulation; therapeutic intervention

\section{Introduction}

In mammals, the immune system is an important part of the body; it can be classified as innate or adaptive according to its origin. The adaptive immune system, which is also called the acquired immune system, includes humoral immunity and cell-mediated immunity [1,2]. In humans, B cells and $\mathrm{T}$ cells are the main kinds of cells involved in acquired immunity [3]. Leukocytes (including phagocytes, mast cells, and natural killer [NK] cells) are the key step of the innate immune system [1]. Dendritic cells (DCs), an important kind of phagocyte that is located in the skin, lungs, and intestines, are the link between the innate and acquired immune systems by presenting antigens to $\mathrm{T}$ cells [4]. Natural killer cells play key roles in clearance of malignant and virally infected cells and regulation of adaptive immune responses in human [5].

On the other hand, cancer is a major cause of death all over the world; there are more than 100 different types of cancer [6]. Environmental and lifestyle factors are the most common risk factors for cancer, accounting for more than $90 \%$ of cases $[7,8]$. For example, $90 \%$ of lung cancers are caused by tobacco smoking, and 10\% of cancers in males and 3\% in females are due to alcohol consumption [9]. Cancer can also be induced by internal factors; while most are not inherited, some are caused by mutated genes [10]. Thus, it is very important that the immune system eliminates viral infections and inflammation to protect the host from cancer and clears away cancer cells [11]. $C D 4^{+}$and $C D 8^{+} \mathrm{T}$ lymphocytes are considered tumor immune cells and have the most important role in immune surveillance [12]. MHC molecules on the surfaces of tumor cells act as the antigen that is recognized by $\mathrm{T}$ cells, allowing NK cells to kill tumor cells $[13,14]$. 


\section{Cancer Immunotherapy}

The main goal of cancer immunotherapy is to specifically inhibit the malignant activity of cancer cells and leave healthy cells unaffected; it has been used to treat many diseases by activating or suppressing the immune system [15-19]. Scientists first considered the use of immunotherapy for allergies [20] and found that it was the most useful method for the treatment of asthma [21, 22]. Better immune targets and combination strategies can harness the immune system by supporting elements of the $\mathrm{T}$ cell anti-tumor response [23], making immunotherapy a useful treatment for all kinds of diseases. Immunotherapy can also be used for cancer, such as breast cancer [24], colon cancer [25], brain tumors [26], glioblastoma [27], lung carcinoma [28], ovarian cancer [29], and prostate cancer [30]. Three exciting targets for immunotherapy, TNF- $a$ converting enzyme, cathepsin $\mathrm{S}$, and urokinase plasmogen activator, have been investigated; rituximab (one of the most commonly used monoclonal antibodies) and trastuzumab have already been used as cancer therapies [31]. As cancer immunotherapy continues to benefit from novel approaches, such as anti-PD1 and anti-CTLA4 antibodies, $I L-2$, and $I F N a$, there will be an increasing need to develop cancer vaccines to guide the immune system specifically toward tumor-associated antigens [32]. IL-2 and IFNa have been approved for the treatment of several different tumors by the FDA. IL-2 can not only mediate $\mathrm{T}$ cell response and cell differentiation [33-35] but also leads to remission in about $10 \%$ patients with metastatic melanoma [36]. IFN can protect the host from infection and tumor invasion [37-39]. Furthermore, Paret found that CXorf61 was a target of immunotherapy in breast cancer [24].

\section{Exosomes in Cancer}

Exosomes are a subset of extracellular vesicles, 30 to $100 \mathrm{~nm}$ in diameter, that function as a mode of intercellular communication and molecular transfer and facilitate the direct extracellular transfer of proteins, lipids, and miRNAs/mRNAs/DNAs between cells. They can be isolated and purified from cell culture supernatants, which are released by many types of cells, such as immune cells and tumor cells [40-42]; they have different biological effects, depending on the type of the original cell, and play an important role in immunoregulation $[43,44]$. It is possible that exosomes are generated, with early endosome formation, in the endocytic pathway [45] and are released to the extracellular matrix by fusing the multi-vesicular bodies with the plasma membrane
$[46,47]$. Because of the different machinery of exosome biogenesis, the kinds of exosomes may be decided by the kinds of multi-vesicular bodies [48]. Exosomes naturally carry RNA and proteins and have specific characteristics with the protein content, including Tsg101, Alix, Gag, Rab, Annexins, Flotilin, CD63, CD81, and Hsp90 [49-52], that can not only transfer messages intercellularly $[53,54]$ but can also modulate the immune response [55-58], which indicates that exosomes can be used for the development of future exosome-based cancer vaccines.

Exosomes can carry various proteins, mRNAs, and miRNAs that result in different actions on the immune system. For example, the exosomes from B cells, combined with MHC-II, can directly stimulate $\mathrm{CD}^{+} \mathrm{T}$ cells [59]; the exosomes from DCs can bind toll-like-receptor ligands and activate bystander DCs [60]; the exosomes from the chicken biliary tract can enhance $\mathrm{CD}^{+} \mathrm{T}$ cell proliferation and inhibit avian leukosis virus replication [61]; the exosomes from leukemic cells can induce an anti-leukemic cytotoxic $\mathrm{T}$ cell immune response [62]; and the exosomes from rheumatoid arthritis patients have a higher amount of TNF than do those from individuals without rheumatoid arthritis [63]. Bhatnagar et al also found that exosomes promoted intercellular communication by activating the immune response and suggested that exosomes containing intracellular pathogens mycobacterium tuberculosis, BCG and salmonella typhimurium are an important mechanism of immune surveillance [64]. Exosomes have a role in mediating autoimmune diseases and inflammation, can induce immune tolerance, and protect against allergic sensitization, which can be used to develop therapy for allergic diseases [65]. On the other hand, Tumor-derived (TD) exosomes have become a new kind of cancer biomarker because they contain proteins, RNAs, and miRNAs and can transfer these to other cells for intercellular communication [66]. The biomarkers in exosomes of ovarian cancer, acute myeloid leukemia, melanoma, and pancreatic adenocarcinoma may be used in cancer diagnoses [67-70]. PCA-3 and TMPRSS2 can be easily detected in these exosomes and can be better biomarkers for prostate cancer [71]. HSP60 is a protein carried by exosomes and can be a biomarker of large bowel cancer in humans [72]. Exosomal $m i R-19 a$ is a biomarker for colorectal cancer [73]. All of these findings will speed up the development of new approaches to cancer diagnosis and treatment.

\section{Immunoregulation of Tumor-Derived Exosomes}

Exosomes from tumor cells are essential in tumor migration and metastasis and play an 
important role in angiogenesis as a vital pathway [74-76]. Tumor-derived (TD) exosomes can suppress the function of NK cells and T cells to affect immunity in cancer, increase tumor growth by interacting with NK cells to decrease perforin secretion, decrease cyclin D3 levels, inhibit Jak-3 [77-79], and promote T regulator cell expansion, leading to the immune escape of tumor cells and inhibition of NK cell cytotoxicity, which is mediated by NKG2D and TGF- $\beta$ [80-82]. TD exosomes are associated with the pro-tumorigenic phenotype; they facilitate immunosuppression and promote the tumorigenesis by inhibiting the immune response [83]. Recently, one study of the immune response of TD exosomes demonstrated that the exosomes triggered $N F-k B$ activation in macrophages, leading to the increased secretion of pro-inflammatory cytokines, such as IL-6, TNF- $a$, and GCSF [84]. The exosomes produced by tumor cells increased the phosphorylation of STAT3 and IL- 6 in DCs, decreasing the cells' activity by inhibiting the differentiation of $\mathrm{CD}^{+} 4^{+}$monocytes to mature antigen-presenting cells (APCs) [85]. Tumor-derived exosomes can affect immunity by decreasing the amount and activity of APCs and increasing the number of myeloid-derived suppressor cells (MDSCs), which is correlated with tumor progression, affects patient survival, and inhibits NK cells and $\mathrm{T}$ lymphocytes [86-89]. FasL-positive exosomes can promote immune escape and induce apoptosis in Kurkat and lymphoid cells [90-92]. When TD exosomes are co-cultured with priming T cells, the expression levels of CD3 and JAK3 are reduced and Fas/FasL promotes cell apoptosis [93]. This increase in suppressive immune cells is one of several mechanisms in immunity that are inhibited by exosomes; other mechanisms include decreases in cell proliferation, $\mathrm{NK}$ and $\mathrm{T}$ cell cytotoxicity, and the number and function of APCs [94,95]. Exosomes carrying TGF- $\beta 1$ can decrease the expression of $N K G 2 D$ receptor and reduce the activation of NK and $\mathrm{CD}^{+} \mathrm{T}$ cells $[96,97]$. Immature DC exosomes display immunosuppressive activity in autoimmune diseases [98].

Although TD exosomes are predominantly immunosuppressive, they can also enhance immunostimulation. The findings of studies investigating the immunoregulation of exosomes in cancer are summarized in Table 1. TD exosomes with APCs can stimulate $\mathrm{T}$ cell responses $[99,100]$. TD exosomes can also enhance anti-tumor immunity through a gene transfer of cytokines, tumor antigens, or heat shock proteins [101-104]. Interestingly, the TD exosomes in bronchoalveolar lavage can induce epithelial cells to produce IL- 8 and activate T cell responses [105]. Moreover, the NK cells co-cultured with TD exosomes can be induced to release granzyme $\mathrm{B}$ and initiate pancreatic cancer cell apoptosis [106].

\section{Immunomodulation in Cancer by Immune Cell-Derived Exosomes}

Exosomes derived from immune cells (such as APCs, dendritic cells, and NK cells) may play a crucial role in the immunomodulation of cancer. First, exosomes with antigen peptides can induce anti-tumor $\mathrm{CD}^{+} \mathrm{T}$ cell responses in murine mastocytoma P815 and mammary carcinoma TS/A cells, causing the regression of an established tumor [107]. Raposo and his colleagues were the first to find that exosomes plus MHC-II can stimulate CD4 T cells [108]. DC-derived (DCD) exosomes can inhibit tumor cell growth by injecting the exosomes into mice with tumors and observing a special anti-tumor immune response [109]. DCD exosomes activated immune effector cells, such as BmDC-derived exosomes with NKG2D, which promoted NK cell activation and proliferation and led to tumor suppression [110]. DCD exosomes carry many of the immune function-associated molecules of DCs and induce antigen-specific responses against tumor cells, which may be used as next-generation cancer immunotherapy [111,112]. High levels of NKG2D on NK cell-derived exosomes can be involved in NK cell-mediated surveillance of the primary tumor $[113,114]$. NK cell-derived exosomes enclose perforin and granzyme $\mathrm{B}$ to mediate anti-tumor activity both in vitro and vivo [115].

\section{Cancer Therapeutic Intervention by Exosomes}

Recently, DC-derived (DCD) exosomes have received attention in cancer immunotherapy because they play key roles in modulating the immune response. Several investigators have demonstrated that these exosomes can be used as cancer vaccines. They have been investigated in the pre-clinical setting because of their ability to stimulate an immune response and eradicate established murine tumors [116-118]. Breast tumor cells co-cultured with DCD exosomes have an increased ability to activate $T$ cells for a more effective response, which suggests that DCD exosomes are another tool in cancer immunotherapy [119]. The anti-tumor efficacy of DCD exosomes was confirmed in melanoma patients [120]. DC immunotherapy by injecting a single dose of DCs loaded with tumor exosomes derived from non-immunogenic tumors, was also found to improve the survival of tumor-bearing mice [121].

The Rab27a- and CD40L- exosomes in tumors 
elicited more potent anti-tumor immune effects, which indicated that these exosomes would be useful vaccines for lung cancer immunotherapy [122,123]. A comparison test showed that DNA vaccines that encode EV-associated antigens are promising immunotherapy tools in cancer and other diseases [119] and that Exo/SEB significantly stimulated apoptosis and raised the expression rates of $B a x, B a k$, and Fas [124]. Näslund found that the inclusion of B-cell epitopes in anti-cancer vaccines was crucial for the success of this immunotherapeutic intervention [125], which demonstrated that exosomes are novel and effective vaccines for treating various cancers and may provide novel insights into the development of efficient exosome-based cancer vaccines. DCD exosomes derived from genetically manipulated DCs, engineered to promote anticancer immunogenicity, which may lead to key advances in cancer therapy [126].

In summary, exosomes can affect the immune system in different ways, depending on the original and tumor microenvironments. No matter how exosomes inhibit the immune response or promote tumor progress, a greater understanding of immunotherapy is needed, and exosomes are likely to become the most effective vaccines for cancer. Further understanding of exosome biology, especially of the molecular mechanisms involved in tumor- and immune cell-derived exosomes as cancer vaccines, is likely to provide significant insights into immunorecognition and therapeutic intervention.

Table 1. Findings in studies investigating the immunoregulation of exosomes in cancers

\begin{tabular}{|c|c|c|c|c|c|}
\hline $\begin{array}{l}\text { Function } \\
\text { in tumor } \\
\text { growth }\end{array}$ & Origin & Cancer cells/immune cells & Targeted molecules & Functional pathways & References \\
\hline \multirow[t]{17}{*}{ Promoting } & $\begin{array}{l}\text { Tumor } \\
\text { cells }\end{array}$ & Colorectal cancer cells & Fas, TNF & Suppressive immune cells & 90 \\
\hline & & Melanoma cells & Fas/FasL & Apoptosis of T cells & 91,82 \\
\hline & & Nasopharyngeal carcinoma cells & Galectin-9/Tim-3 & Induce apoptosis of T cells & 92 \\
\hline & & Solid tumor/AML cells & JAK3, Fas/FasL & Suppress T cell and NK cells & 93 \\
\hline & & Breast cancer cells & NF-kappa B & Decrease T cell number & 84 \\
\hline & & Mammary carcinoma cells & $\begin{array}{l}\text { Perforin, cyclin D3, } \\
\text { JAK3 }\end{array}$ & Suppress NK cell function & 77 \\
\hline & & Ovarian tumor cells & FasL & T cell apoptosis, suppress T cell receptor & 79 \\
\hline & & Acute myeloid leukemia cells & TGF- $\beta 1$ & Suppress NK cell function & 80 \\
\hline & & Mesothelioma cells & NKG2D & Suppress T cell and NK cell function & 96 \\
\hline & & Squamous cell carcinoma cells & Fas/FasL & Promoting T regulatory cell expansion & 82 \\
\hline & & Melanoma cells & & Promote T regulatory cell expansion & 82 \\
\hline & & Murine mammary tumor cells & IL-6 & DC differentiation & 86 \\
\hline & & Mammary adenocarcinoma cells & $\begin{array}{l}\text { IL-6, VEGF, PGE2, } \\
\text { TGF- } \beta\end{array}$ & Accumulation of myeloid-derived suppressor cells & 88 \\
\hline & & $\begin{array}{l}\text { Colon carcinoma CT26 cells, } \\
\text { lymphoma EL4 cells, embryo } \\
\text { NIH/3T3 fibroblasts, lung } \\
\text { adenocarcinoma H23 cells, } \\
\text { mammary adenocarcinoma cells }\end{array}$ & Hsp72, TLR2, STAT3 & $\begin{array}{l}\text { Activation and enhancement of MDSCs' } \\
\text { suppressive ability }\end{array}$ & 75 \\
\hline & & Ovarian cancer cells & $\begin{array}{l}\text { ATF2, MTA1, } \\
\text { ROCK1/2 }\end{array}$ & Angiogenesis in ovarian serous cancer & 76 \\
\hline & & $\begin{array}{l}\text { Squamous carcinoma A431 cells, } \\
\text { MDA-MB-231 breast } \\
\text { adenocarcinoma cells, A549 NSCL } \\
\text { cells, H1299 NSCL cells }\end{array}$ & Hx or Reox & Regulation of tumor metastasis and angiogenesis & 98 \\
\hline & & Pancreatic adenocarcinoma cells & $\begin{array}{l}\text { Tetraspanin } \\
\text { D6.1A/CO-029 }\end{array}$ & Induce systemic angiogenesis & 99 \\
\hline \multirow[t]{10}{*}{ Inhibiting } & $\begin{array}{l}\text { Tumor } \\
\text { cells }\end{array}$ & Non-small cell lung cancer cells & MAGE peptides & $\mathrm{T}$ cell responses and NK cell lytic activity increased & 101 \\
\hline & & Fibrosarcoma cells & C1C2-fused antigen & $\begin{array}{l}\text { Induction of a more potent antigen-specific } \\
\text { anti-tumor immune response in vivo }\end{array}$ & 103 \\
\hline & & Murine lymphoma E.G7-OVA cells & SEA-TM & $\begin{array}{l}\text { Promote induction of specific anti-tumor immune } \\
\text { response }\end{array}$ & 104 \\
\hline & & $\begin{array}{l}\text { Murine colon carcinoma cells, } \\
\text { murine melanoma cells }\end{array}$ & HSP70 & Improve immunostimulatory activities & 106 \\
\hline & & $\begin{array}{l}\text { Human pancreas cells, human colon } \\
\text { cells }\end{array}$ & HSP70 & $\begin{array}{l}\text { Stimulate migratory and cytolytic activity of NK } \\
\text { cells }\end{array}$ & 108 \\
\hline & APCs & Autologous monocyte derived DCs & $\begin{array}{l}\text { MAGE3 peptides, } \\
\text { HLA-A2, HLA-BC }\end{array}$ & T cell responses & 102 \\
\hline & & Spleen-derived murine D1 DCs & $\begin{array}{l}\text { HSC73, MHCII, Mac-1 } \\
\text { integrin, CD9, MFG-E8 }\end{array}$ & Elicit potent $\mathrm{T}$ cell-dependent immune responses & 110 \\
\hline & & DCs & NKG2D, IL-15Ralpha & Promote NK cell activation and proliferation & 115 \\
\hline & & DCs & MHCII & Elicit $\mathrm{T}$ cell-dependent immune responses & 113 \\
\hline & & NK cells & FasL, CD56, perforin & Deliver cytotoxic molecules & 114 \\
\hline
\end{tabular}




\section{Acknowledgments}

This work was sponsored by the grant (Jin Wang) from the Shanghai Pujiang Program, and the grant (SHDC12014104) from Shanghai ShenKang Hospital Development Center for the establishment of early warning and emergency treatment technology for high pathogenic respiratory diseases, the grant (15DZ2290200) from Shanghai Science and Technology Commission, Shanghai, China.

\section{Competing Interests}

The authors have declared that no competing interest exists.

\section{References}

1. Alberts B, Johnson A, Lewis J, et al. Molecular Biology of the Cell; Fourth Edition. Garland Science. 2002.

2. Kawai $\mathrm{T}$, Akira $\mathrm{S}$. Innate immune recognition of viral infection. Nature Immunology $2006 ; 7$ (2): 131-7.

3. Janeway CA. Immunobiology. Garland Science. 2005

4. Guermonprez P, Valladeau J, Zitvogel L, et al. Antigen presentation and T cell stimulation by dendritic cell. Annu Rev Immunol. 2002; 20 (1): 621-67.

5. Rajalingam R. Overview of the killer cell immunoglobulin-like receptor system. Methods Mol Biol. 2012; 882: 391-414.

6. Siegel RL, Miller KD, Jemal A. Cancer statistics, 2015. CA Cancer J Clin. 2015; 65(1): 5-29.

7. Anand $\mathrm{P}$, Kunnumakara $\mathrm{AB}$, Sundaram $\mathrm{C}$, et al. Cancer is a preventable disease that requires major lifestyle changes. Pharm Res. 2008; 25(9): 2097-116.

8. Biesalski HK, Bueno de Mesquita B, Chesson A, et al. European Consensus Statement on Lung Cancer: risk factors and prevention. Lung Cancer Panel. CA Cancer J Clin. 1998; 48(3): 167-76; discussion 164-6.

9. Schütze $\mathrm{M}$, Boeing $\mathrm{H}$, Pischon $\mathrm{T}$, et al. Alcohol attributable burden of incidence of cancer in eight European countries based on results from prospective cohort study. BMJ. 2011; 342: d1584.

10. Roukos DH. Genome-wide association studies: how predictable is a person's cancer risk? Expert Rev Anticancer Ther. 2009; 9(4): 389-92.

11. Swann JB, Smyth MJ. Immune surveillance of tumors. J Clin Invest. 2007; 117(5): 1137-46.

12. de Visser KE, Eichten A, Coussens LM. Paradoxical roles of the immune system during cancer development. Nat Rev Cancer. 2006; 6: 24-37.

13. Seliger B, Ritz U, Ferrone S. Molecular mechanisms of HLA class I antigen abnormalities following viral infection and transformation. Int J Cancer. 2006; 118 (1): 129-38

14. Hayakawa Y, Smyth MJ. Innate immune recognition and suppression of tumors. Advances in Cancer Research. Adv Cancer Res. 2006; 95: 293-322.

15. Chatenoud L. Immune therapies of autoimmune diseases: are we approaching a real cure? Curr Opin Immunol. 2006; 18: 710-7.

16. Paulis LE, Mandal S, Kreutz M, et al. Dendritic cell-based nanovaccines for cancer immunotherapy. Curr Opin Immunol. 2013; 25: 389-95.

17. Forghani P, Waller EK. Poly (I: C) modulates the immunosuppressive activity of myeloid-derived suppressor cells in a murine model of breast cancer. Breast Cancer Res Treat. 2015; 153(1): 21-30.

18. Bayless H, Schneider S. Nivolumab: immunotherapy in malignant melanoma. Clin J Oncol Nurs. 2015; 19(4): 430-2

19. Taniguchi M, Harada M, Dashtsoodol N, et al. Discovery of NKT cells and development of NKT cell-targeted anti-tumor immunotherapy. Proc Jpn Acad Ser B Phys Biol Sci. 2015; 91(7): 292-304.

20. Anagnostou K, Clark A. Oral immunotherapy for peanut allergy. Annu Rev Med. 2015.

21. Siebeneicher S, Reuter S, Wangorsch A, et al. Epicutaneous immunotherapy with a hypoallergenic Betv 1 suppresses allergic asthma in a murine model. Allerg. 2015.

22. Normansell R, Kew KM, Bridgman AL. Sublingual immunotherapy for asthma. Cochrane Database Syst Rev. 2015; 8: CD011293.

23. Tchekmedyian N, Gray JE, Creelan BC, et al. Propelling Immunotherapy Combinations Into the Clinic. Oncology (Williston Park). 2015; 29(12). pii: 214814

24. Paret $\mathrm{C}$, Simon $\mathrm{P}$, Vormbrock $\mathrm{K}$, et al. CXorf61 is a target for $\mathrm{T}$ cell based immunotherapy of triple-negative breast cancer. Oncotarget. 2015; 6(28): 25356-67.

25. Downs-Canner S, Magge D, Ravindranathan R, et al. Complement inhibition: a novel form of immunotherapy for colon cancer. Ann Surg Oncol. 2015.

26. Finocchiaro G, Pellegatta S. Novel mechanisms and approaches in immunotherapy for brain tumors. Discov Med. 2015; 20(108): 7-15.
27. Everson RG, Antonios JP, Lisiero DN, et al. Efficacy of systemic adoptive transfer immunotherapy targeting NY-ESO-1 for glioblastoma. Neuro Oncol. 2015; pii: nov153.

28. Laban S, Doescher J, Schuler PJ, et al. Immunotherapy of head and neck tumors: highlights of the ASCO Meeting 2015. HNO. 2015; 63(9): 612-9.

29. Huang RY, Eppolito C, Lele S, et al. LAG3 and PD1 co-inhibitory molecules collaborate to limit CD8+ T cell signaling and dampen antitumor immunity in a murine ovarian cancer model. Oncotarget. 2015; 6(29): 27359-77.

30. Kwilas AR, Ardiani A, Dirmeier U, et al. A poxviral-based cancer vaccine targeting the transcription factor twist inhibits primary tumor growth and metastases in a model of metastatic breast cancer and improves survival in a spontaneous prostate cancer model. Oncotarget. 2015; 6(29): 28194-210.

31. Neves H, Kwok HF. Recent advances in the field of anti-cancer immunotherapy. BBA Clin. 2015; 3:280-8.

32. Hammerich L, Binder A, Brody JD. In situ vaccination: cancer immunotherapy both personalized and off-the-shelf. Mol Oncol. 2015; 9 (10): 1966-81.

33. Szabo SJ, Sullivan BM, Peng SL, et al. Molecular mechanisms regulating Th1 immune responses. Annu Rev Immunol. 2003; 21: 713-58.

34. Littman DR, Rudensky AY. Th17 and regulatory T cells in mediating and restraining inflammation. Cell. 2010; 140(6): 845-58.

35. Paul WE, Zhu J. How are $\mathrm{T}(\mathrm{H})$ 2-type immune responses initiated and amplified? Nat Rev Immunol. 2010; 10(4): 225-35.

36. Atkins MB, Lotze MT, Dutcher JP, et al. High-dose recombinant interleukin 2 therapy for patients with metastatic melanoma: analysis of 270 patients treated between 1985 and 1993. J Clin Oncol. 1999; 17(7): 2105-16.

37. Keilholz U, Conradt C, Legha SS, et al. Results of interleukin-2-based treatment in advanced melanoma: a case record-based analysis of 631 patients. J Clin Oncol. 1998; 16(9): 2921-9.

38. Kotredes KP, Gamero AM. Interferons as inducers of apoptosis in malignant cells. J Interferon Cytokine Res. 2013; 33(4): 162-70.

39. Rees RC. MHC restricted and non-restricted killer lymphocytes. Blood Rev. 1990; 4(3): 204-10.

40. Keller S, Sanderson MP, Stoeck A, et al. Exosomes: from biogenesis and secretion to biological function. Immunol Lett. 2006; 107: 102-8.

41. Goligorsky MS, Addabbo F, O Riordan E. Diagnostic potential of urine proteome: a broken mirror of renal diseases. J Am Soc Nephrol. 2007; 18(8): 2233-9.

42. Admyre $\mathrm{C}$, Johansson SM, Qazi KR, et al. Exosomes with immune modulatory features are present in human breast milk. J Immunol. 2007; 179(3): 1969-78.

43. Chalmin F, Ladoire S, Mignot G, et al. Membrane-associated Hsp72 from tumor-derived exosomes mediates STAT3-dependent immunosuppressive function of mouse and human myeloid-derived suppressor cells. J Clin Invest. 2010, 120(2): 457-71.

44. Sun D, Zhuang X, Zhang S, et al. Exosomes are endogenous nanoparticles that can deliver biological information between cells. Adv Drug Deliv Rev. 2013; 65: $342-47$

45. Johnstone RM, Adam M, Hammond JR, et al. Vesicle formation during reticulocyte maturation. Association of plasma membrane activities with released vesicles (exosomes). J Biol Chem. 1987; 262(2): 9412-20.

46. Fevrier B, Raposo G. Exosomes: endosomal-derived vesicles shipping extracellular messages. Curr Opin Cell Biol. 2004; 16(4): 415-21.

47. Thery C, Zitvogel L, Amigorena S. Exosomes: composition, biogenesis and function. Nat Rev Immunol. 2002; 2(8): 569-79.

48. Frydrychowicz M, Kolecka-Bednarczyk A, Madejczyk $M$, et al. Exosomes-structure, biogenesis and biological role in non-small-cell lung cancer. Scand J Immunol. 2015; 81(1): 2-10.

49. Thery C. Exosomes: secreted vesicles and intercellular communications. F1000 Biol Rep. 2011; 3: 15.

50. Zoller M. Tetraspanins: push and pull in suppressing and promoting metastasis. Nat Rev Cancer. 2009; 9(1): 40-55.

51. Futter CE, White IJ. Annexins and endocytosis. Traffic. 2007; 8(8): 951-8.

52. Gastpar R, Gehrmann M, Bausero MA, et al. Heat shock protein 70 surface positive tumor exosomes stimulate migratory and cytolytic activity of natural killer cells. Cancer Res. 2005; 65(12): 5238-47.

53. Ridder K, Sevko A, Heide J, et al. Extracellular vesicle-mediated transfer of functional RNA in the tumor microenvironment. Oncoimmunology. 2015; 4(6): e1008371

54. Dutta S, Reamtong O, Panvongsa W, et al. Proteomics profiling of cholangiocarcinoma exosomes: a potential role of oncogenic protein transferring in cancer progression. Biochim Biophys Acta. 2015; 1852(9): 1989-99.

55. Anand PK. Exosomal membrane molecules are potent immune response modulators. Commun Integr Biol. 2010; 3: 405-8.

56. Chalmin F, Ladoire S, Mignot G, et al. Membrane-associated Hsp72 from tumor-derived exosomes mediates STAT3-dependent immunosuppressive function of mouse and human myeloid-derived suppressor cells. J Clin Invest. 2010; 120(2): 457-71.

57. Robbins PD, Morelli AE. Regulation of immune responses by extracellular vesicles. Nat Rev Immunol. 2014; 14(3): 195-208.

58. Yi H, Ye J, Yang XM, et al. High-grade ovarian cancer secreting effective exosomes in tumor angiogenesis. Int J Clin Exp Pathol. 2015; 8(5): 5062-70.

59. Raposo G, Nijman HW, Stoorvogel $W$, et al. B lymphocytes secrete antigen-presenting vesicles. J Exp Med. 1996; 183(3): 1161-72. 
60. Sobo-Vujanovic A, Munich S, Vujanovic NL. Dendritic-cell exosomes cross-present Toll-like receptor-ligands and activate bystander dendritic cells. Cell Immunol. 2014; 289(1-2): 119-27.

61. Wang Y, Wang G, Wang Z, et al. Chicken biliary exosomes enhance CD4(+)T proliferation and inhibit ALV-J replication in liver. Biochem Cell Biol. 2014; 92(2): 145-51.

62. Yao Y, Wang C, Wei W, et al. Dendritic cells pulsed with leukemia cell-derived exosomes more efficiently induce antileukemic immunities. PLoS One. 2014; 9(3): e91463.

63. Zhang HG, Liu C, Su K, et al. A membrane form of TNF-alpha presented by exosomes delays $\mathrm{T}$ cell activationinduced cell death. J Immunol, 2006; 176(12): 7385-93.

64. Bhatnagar S, Shinagawa K, Castellino FJ, et al. Exosomes released from macrophages infected with intracellular pathogens stimulate a proinflammatory response in vitro and in vivo. Blood. 2007; 110(9): 3234-44.

65. Prado N, Marazuela EG, Segura E, et al. Exosomes from bronchoalveolar fluid of tolerized mice prevent allergic reaction. J Immunol, 2008; 181:1519-25.

66. Naito Y, Yoshioka Y, Ochiya T. The functional role of exosomes in cancer biology and their potential as biomarkers and therapeutic targets of cancer. Gan To Kagaku Ryoho. 2015; 42(6): 647-55.

67. Szajnik M, Derbis M, Lach M, et al. Exosomes in plasma of patients with ovarian carcinoma: potential biomarkers of tumor progression and response to therapy. Gynecol Obstet (Sunnyvale). 2013; Suppl 4: 3.

68. Hornick NI, Huan J, Doron B, et al. Serum exosome microRNA as a minimally-invasive early biomarker of AML. Sci Rep. 2015; 5:11295.

69. Peinado H, Alečković M, Lavotshkin S, et al. Melanoma exosomes educate bone marrow progenitor cells toward a pro-metastatic phenotype through MET. Nat Med. 2012; 18(6):883-91.

70. Que R, Ding G, Chen J, et al. Analysis of serum exosomal microRNAs and clinicopathologic features of patients with pancreatic adenocarcinoma. World J Surg Oncol. 2013; 11: 219.

71. Nilsson J, Skog J, Nordstrand A, et al. Prostate cancer-derived urine exosomes: a novel approach to biomarkers for prostate cancer. Br J Cancer. 2009; 100(10): 1603-7.

72. Campanella C, Rappa F, Sciumè C, et al. Heat shock protein 60 levels in tissue and circulating exosomes in human large bowel cancer before and after ablative surgery. Cancer. 2015; 121(18): 3230-39.

73. Matsumura T, Sugimachi $\mathrm{K}$, Iinuma $\mathrm{H}$, et al. Exosomal microRNA in serum is a novel biomarker of recurrence in human colorectal cancer. Br J Cancer. 2015; 113(2): 275-81.

74. Yi $\mathrm{H}$, Ye J, Yang $\mathrm{XM}$, et al. High-grade ovarian cancer secreting effective exosomes in tumor angiogenesis. Int J Clin Exp Pathol. 2015; 8(5):5062-70.

75. Park JE, Tan HS, Datta A, et al. Hypoxic tumor cell modulates its microenvironment to enhance angiogenic and metastatic potential by secretion of proteins and exosomes. Mol Cell Proteomics. 2010; 9: 1085-99.

76. Gesierich S, Berezovskly I, Ryschich E, et al. Systemic induction of the angiogenesis switch by the tetraspanin D6.1A/CO-029. Cancer Res. 2006; 66: 7083-94

77. Liu C, Yu S, Zinn K, et al. Murine mammary carcinomas exosomes promote tumor growth by suppression of NK cell function. J Immunol. 2006; 176: 1375-85.

78. Kim $\mathrm{SH}$, Bianco $\mathrm{N}$, Menon $\mathrm{R}$, et al. Exosomes derived from genetically modified DC expressing FasL are anti-inflammatory and immunosuppressive. Mol Ther. 2006; 13: 289-300.

79. Taylor DD, Gerçel-Taylor C, Lyons KS, et al. T-cell apoptosis and suppression of T-cell receptor/CD3-zeta by Fas ligand-containing membrane vesicles shed from ovarian tumors. Clin Cancer Res. 2003; 9: 5113-9.

80. Szczepanski MJ, Szajnik M, Welsh A, et al. Blast-derived microvesicles in sera from patients with acute myeloid leukemia suppress natural killer cell function via membrane-associated transforming growth factor-beta1. Haematologica. 2011; 96(9): 1302-9.

81. Ashiru $\mathrm{O}$, Boutet $\mathrm{P}$, Fernandez-Messina $\mathrm{L}$, et al. Natural killer cell cytotoxicity is suppressed by exposure to the human NKG2D ligand MICA*008 that is shed by tumor cells in exosomes. Cancer Res. 2010; 70: 481-9.

82. Wieckowski EU, Visus C, Szajnik M, et al. Tumor-derived microvesicles promote regulatory $\mathrm{T}$ cell expansion and induce apoptosis in tumor reactive activated CD8+ T lymphocytes. J. Immunol. 2009; 183(6): 3720-30.

83. Filipazzi P, Burdek M, Villa A, et al. Recent advances on the role of tumor exosomes in immunosuppression and disease progression. Semin Cancer Biol. 2012; $22: 342-9$

84. Chow A, Zhou W, Liu L, et al. Macrophage immuno-modulation by breast cancer derived exosomes requires Toll-like receptor 2-mediated activation of NF-kappaB. Sci Rep. 2014; 4: 5750

85. Yu S, Liu C, Su K, et al. Tumor exosomes inhibit differentiation of bone marrow dendritic cells. J Immunol. 2007; 178: 6867-75.

86. Gabrilovich DI, Nagaraj S. Myeloid-derived suppressor cells as regulators of the immune system. Nat Rev Immunol. 2009; 9: 162-74.

87. Xiang $\mathrm{X}$, Poliakov A, Liu C, et al. Induction of myeloid-derived suppressor cells by tumor exosomes. Int J Cancer. 2009; 124(11): 2621-33.

88. Liu C, Yu S, Kappes J, et al. Expansion of spleen myeloid suppressor cells represses NK cell cytotoxicity in tumor-bearing host. Blood. 2007; 109: 4336-42.

89. Chalmin F, Ladoire S, Mignot G, et al. Membrane-associated Hsp72 from tumor-derived exosomes mediates STAT3-dependent immunosuppressive function of mouse and human myeloid-derived suppressor cells. J Clin Invest. 2010; 120: 457-71.
90. Huber V, Fais S, Iero M, et al. Human colorectal cancer cells induce T-cell death through release of proapoptotic microvesicles: role in immune escape. Gastroenterology. 2005; 128(7): 1796-804.

91. Andreola G, Rivoltini L, Castelli C, et al. Induction of lymphocyte apoptosis by tumor cell secretion of FasL-bearing microvesicles. J Exp Med. 2002; 195: 1303-16.

92. Klibi J, Niki T, Riedel A, et al. Blood diffusion and Th1-suppressive effects of galectin-9-containing exosomes released by Epstein-Barr virus-infected nasopharyngeal carcinoma cells. Blood. 2009; 113(9): 1957-66.

93. Whiteside TL. Immune modulation of T-cell and NK (natural killer) cell activities by TEXs (tumour-derived exosomes). Biochem Soc Trans. 2013; 41(1): 245-51.

94. Zhang HG, Grizzle WE. Exosomes and cancer: a newly described pathway of immune suppression. Clin Cancer Res. 2011; 17(5): 1-6.

95. Zhang HG, Liu Y, Deng ZB, et al. Exosomes and immune surveillance of neoplastic lesions: a review. Biotech Histochem. 2012; 87: 161-8.

96. Clayton A, Mitchell JP, Court J, et al. Human tumor-derived exosomes down-modulate NKG2D expression. J Immunol. 2008; 180: 7249-58.

97. Espinoza JL, Takami A, Yoshioka K, et al. Human microRNA-1245 down-regulates the NKG2D receptor in natural killer cells and impairs NKG2D-mediated functions. Haematologica. 2012; 97(9):1295-303.

98. Bu N, Wu HQ, Zhang GL, et al. Immature dendritic cell exosomes suppress experimental autoimmune myasthenia gravis. J Neuroimmunol. 2015; 285 : $71-5$.

99. Morse MA, Garst J, Osada T, et al. A phase I study of dexosome immunotherapy in patients with advanced nonsmall cell lung cancer. J Transl Med. 2005; 3(1): 9 .

100. Escudier B, Dorval T, Chaput N, et al. Vaccination of metastatic melanoma patients with autologous dendritic cell (DC) derived-exosomes: results of the first phase I clinical trial. J Transl Med. 2005; 3(1): 10.

101. Zeelenberg IS, Ostrowski M, Krumeich S, et al. Targeting tumor antigens to secreted membrane vesicles in vivo induces efficient antitumor immune responses. Cancer Res. 2008; 68(4):1228-35

102. Xiu F, Cai Z, Yang Y, et al. Surface anchorage of superantigen SEA promotes induction of specific antitumor immune response by tumor-derived exosomes. J Mol Med (Berl). 2007; 85(5): 511-21.

103. Chen W, Wang J, Shao C, et al. Efficient induction of antitumor $\mathrm{T}$ cell immunity by exosomes derived from heat-shocked lymphoma cells. Eur J Immunol. 2006; 36(6): 1598-607.

104. Cho JA, Lee YS, Kim SH, et al. MHC independent anti-tumor immune responses induced by Hsp70-enriched exosomes generate tumor regression in murine models. Cancer Lett. 2009; 275(2): 256-65.

105. Qazi KR, Torregrosa Paredes P, Dahlberg B, et al. Proinflammatory exosomes in bronchoalveolar lavage fluid of patients with sarcoidosis. Thorax. 2010; 65(11): 1016-24.

106. Gastpar R, Gehrmann M, Bausero MA, et al. Heat shock protein 70 surface-positive tumor exosomes stimulate migratory and cytolytic activity of natural killer cells. Cancer Res. 2005; 65:5238-47.

107. Zitvogel L, Regnault A, Lozier A, et al. Eradication of established murine tumors using a novel cell-free vaccine: dendritic cell derived exosomes. Nat Med. 1998; 4(5): 594-600.

108. Baleeiro RB, Anselmo LB, Soares FA, et al. High frequency of immature dendritic cells and altered in situ production of interleukin-4 and tumor necrosis factor-alpha in lung cancer. Cancer Immunol Immunother. 2008; 57(9): 1335-45.

109. Thery C, Regnault A, Garin J, et al. Molecular characterization of dendritic cell derived exosomes. Selective accumulation of the heat shock protein hsc73. J Cell Biol. 1999; 47(3): 599-610.

110. Viaud S, Terme M, Flament $C$, et al. Dendritic cell derived exosomes promote natural killer cell activation and proliferation: a role for NKG2D ligands and IL-15Ralpha. PLoS ONE. 2009; 4(3): e4942.

111. Romagnoli GG, Zelante BB, Toniolo PA, et al. Dendritic Cell-Derived Exosomes may be a Tool for Cancer Immunotherapy by Converting Tumor Cells into Immunogenic Targets. Front Immunol. 2015; 5: 692.

112. Bell BM, Kirk ID, Hiltbrunner S, et al. Designer exosomes as next-generation cancer immunotherapy. Nanomedicine. 2016; 12(1): 163-9.

113. Guerra N, Tan YX, Joncker NT, et al. NKG2D-Deficient mice are defective in tumor Surveillance in Models of Spontaneous Malignancy. Immunity. 2008; 28(4): 571-80.

114. Bauer S, Groh V, Wu J, et al. Activation of NK cells and T cells by NKG2D, a receptor for stress-inducible MICA. Science. 1999; 285(5428): 727-9.

115. Lugini L, Cecchetti S, Huber V, et al. Immune surveillance properties of human NK cell-derived exosomes. J Immunol. 2012; 189: 2833-42.

116. Chaput N, Schartz NE, Andre F, et al. Exosomes as potent cell-free peptide-based vaccine. II. Exosomes in $\mathrm{CpG}$ adjuvants efficiently prime naive Tc1 lymphocytes leading to tumor rejection. J Immunol. 2004; 172(4): 2137-46.

117. Amigorena S. Anti-tumour immunotherapy using dendritic cell-derived exosomes. Res Immunol. 1998; 149(7-8): 661-2.

118. Romagnoli GG, Zelante BB, Toniolo PA, et al. Dendritic cell derived exosomes may be a tool for cancer immunotherapy by converting tumor cells into immunogenic targets. Front Immunol. 2015; 5: 692.

119. Sedlik C, Vigneron J, Torrieri-Dramard L, et al. Different immunogenicity but similar antitumor efficacy of two DNA vaccines coding for an antigen secreted in different membrane vesicle-associated forms. J Extracell Vesicles. 2014; 3 
120. Escudier B, Dorval T, Chaput N, et al. Vaccination of metastatic melanoma patients with autologous dendritic cell (DC) derived-exosomes: results of thefirst phase I clinical trial. J Transl Med. 2005; 3(1): 10.

121. Mahaweni NM, Kaijen-Lambers ME, Dekkers J, et al. Tumour derived exosomes as antigen delivery carriers in dendritic cell based immunotherapy for malignant mesothelioma. J Extracell Vesicles. 2013; 2.

122. Wang J, Wang L, Lin $Z$, et al. More efficient induction of antitumor $\mathrm{T}$ cell immunity by exosomes from CD40L gene-modified lung tumor cells. Mol Med Rep. 2014; 9(1): 125-31

123. Li W, Mu D, Tian F, et al. Exosomes derived from Rab27a overexpressing tumor cells elicit efficient induction of antitumor immunity. Mol Med Rep. 2013; 8(6): 1876-82

124. Mahmoodzadeh Hosseini H, Ali Imani Fooladi A, Soleimanirad J, et al . Exosome/staphylococcal enterotoxin B, an anti tumor compound against pancreatic cancer. J BUON. 2014; 19(2): 440-8

125. Näslund TI, Gehrmann U, Gabrielsson S. Cancer immunotherapy with exosomes requires B-cell activation. Oncoimmunology. 2013; 2(6): e24533.

126. Pitt JM, Charrier M, Viaud S, et al. Dendritic cell-derived exosomes as immunotherapies in the fight against cancer. J Immunol. 2014; 193(3): 1006-11. 